\title{
Acromegaly caused by growth hormone-releasing hormone-producing tumors: long-term observational studies in three patients
}

\author{
Nienke R. Biermasz · Jan W. A. Smit - Alberto M. Pereira • \\ Marijke Frölich · Johannes A. Romijn · Ferdinand Roelfsema
}

Published online: 31 May 2007

(C) Springer Science+Business Media, LLC 2007

\begin{abstract}
We report on three newly diagnosed patients with extracranial ectopic GHRH-associated acromegaly with long-term follow-up after surgery of the primary tumor. One patient with a pancreatic tumor and two parathyroid adenomas was the index case of a large kindred of MEN-I syndrome. The other two patients had a large bronchial carcinoid. The first patient is still in remission now almost 22 years after surgery. In the two other patients GHRH did not normalize completely after surgery and they are now treated with slow-release octreotide. IGF-I normalized in all patients. During medical treatment basal GH secretion remained (slightly) elevated and secretory regularity was decreased in $24 \mathrm{~h}$ blood sampling studies. We did not observe development of tachyphylaxis towards the drug or radiological evidence of (growing) metastases. We propose life-long suppressive therapy with somatostatin analogs in cases with persisting elevated serum GHRH concentrations after removal of the primary tumor. Independent parameters of residual disease are elevated basal (nonpulsatile) GH secretion and decreased GH secretory regularity.
\end{abstract}

Keywords Acromegaly - Ectopic GHRH - Octreotide · Approximate entropy $\cdot$ GH secretion

N. R. Biermasz · J. W. A. Smit - A. M. Pereira .

M. Frölich · J. A. Romijn · F. Roelfsema ( $₫)$

Department of Endocrinology and Metabolic Diseases, Leiden

University Medical Center, Albinusdreef 2, Leiden 2333 ZA,

The Netherlands

e-mail: f.roelfsema@lumc.nl

\section{Introduction}

Acromegaly caused by ectopic extracranial growth hormone-releasing hormone (GHRH) secretion is a very rare disorder occurring probably in less than $1 \%$ of the acromegalic patients [1]. The majority of the GHRH-secreting tumors are bronchial carcinoids. Other GHRH-secreting tumors in decreasing order of occurrence are pancreatic adenomas, gastro-intestinal tumors, thymic tumors, and tumors associated with the MEN-I syndrome [2].

Here we report our clinical experience in three patients with the ectopic GHRH-syndrome derived from a population of over 200 acromegalic patients, diagnosed and treated at the Leiden University Medical Center from 1976 till 2002. Long-term follow-up studies in these patients and results of medical therapy with somatostatin analogs are scarce. The purpose of this report is to expand our knowledge of this rare clinical entity. In addition, we report detailed results of diurnal GH secretion, before and after removal of the GHRH-producing source in order to investigate whether pulsatile and basal GH secretion due to GHRH overproduction differs from that of a primary pituitary somatotropinoma.

\section{Methods}

Basal concentrations of hormones, including prolactin, free thyroxin, triiodothyronine, cortisol, testosterone, estradiol, progesterone, IGF-I, and IGFBP3 were measured. In addition the following tests were performed: Oral glucose loading test $(75 \mathrm{~g})$, TRH test $(200 \mu \mathrm{g}$ i.v. $)$, and a GHRH test $(50 \mu \mathrm{g}$ i.v. $)$ and the following hormones were measured: glucose tolerance test: $\mathrm{GH}$, insulin and glucose at 0 , 30, 60, 90 and $120 \mathrm{~min}$, TRH test: TSH, prolactin and $\mathrm{GH}$ 
at $-15,0,15,20,3045,60,90$ and $120 \mathrm{~min}$; GHRH test: GH and prolactin at $0,20,30,45,60$, and $90 \mathrm{~min}$. For the 24-h GH secretion profile the patients were hospitalized, and an indwelling i.v. cannula was inserted in a forearm vein, and blood samples were withdrawn at 10 -min intervals. The patients were free to move around, but not to sleep during daytime. Meals were served at 0800, 1230 and $1730 \mathrm{~h}$. Lights were turned off between 2200 and $2400 \mathrm{~h}$.

\section{Assays}

Plasma GH was measured with a sensitive time-resolved fluoro-immunoassay (Wallac Oy, Turku, Finland). The assay is specific for the $22 \mathrm{kDa} \mathrm{GH}$. The standard was biosynthetic recombinant human GH (Genotropin, Pharmacia \& Upjohn, Uppsala, Sweden), and was calibrated against the WHO First International Reference Preparation $80 / 505$ (to convert $\mu \mathrm{g} / \mathrm{l}$ to $\mathrm{mU} / \mathrm{l}$ multiply by 2.6 ). The limit of detection of this assay (defined as the value $2 \mathrm{SD}$ above the mean value of the zero standard) was $0.01 \mathrm{mU} / \mathrm{l}$ $(0.0038 \mathrm{ng} / \mathrm{ml})$. The intraassay coefficient of variation varied between $1.6 \%$ and $8.4 \%$ in the range from $0.01 \mu \mathrm{g} / \mathrm{l}$ to $18 \mu \mathrm{g} / \mathrm{l}$ and interassay coefficient of variation was 2.0 $9.0 \%$ in the same range.

Total IGF-I was determined by RIA (Incstar, Stillwater, MN) after extraction and purification on ODS-silica columns. The intraassay coefficient of variation was less than 11\%. The detection limit was $1.5 \mathrm{nmol} / \mathrm{l}$. Age-related normal data were determined in the same laboratory. The measurement of IGFBP3 was performed by RIA (Nichols Institute Diagnostics, San Juan Capistrano, CA). The limit of detection of this assay was $0.08 \mathrm{mg} / \mathrm{l}$, and the interassay coefficient variation was below $6.8 \%$.

\section{Deconvolution analysis}

A multiparameter deconvolution technique was used to estimate relevant measures of $\mathrm{GH}$ secretion from the 24-h serum GH concentration profiles, as described previously [3]. Initial estimates of basal GH secretion rate were calculated to approximate the lowest $5 \%$ of all plasma $\mathrm{GH}$ concentrations in the time series. Peak detection entailed application of $95 \%$ statistical confidence intervals to two thirds of all GH secretory peaks considered jointly and individual 95\% statistical confidence intervals to the remaining one third smaller pulses, as validated in simulations [4]. The following four secretory and clearance measures of interest were estimated: (1) the number and locations of secretory events; (2) the amplitudes of secretory bursts; (3) the durations of randomly dispersed GH secretory bursts; and (4) the endogenous single component subject specific plasma half-life of GH. It was assumed the GH distribution volume and half-life were time and concentration invariant. The following parameters were calculated: Half-duration of secretory bursts (duration of the secretory burst at half-maximal amplitude), hormone half-life, burst frequency, amplitude of the secretory burst (maximal secretory rate attained within a burst), mass secreted per burst, basal secretion rate, pulsatile secretion rate (product of burst frequency and mean burst mass) and total secretion (sum of basal and pulsatile).

\section{Approximate entropy}

The univariate approximate entropy (ApEn) statistic was developed to quantify the degree of irregularity, or disorderliness, of a time series [5]. Technically, ApEn quantifies the summed logarithmic likelihood that templates (of length $m$ ) of patterns in the data that are similar (within $r$ ), remain similar (within the same tolerance $r$ ) on next incremental comparison and has been formally defined elsewhere [6]. The ApEn calculation provides a single non-negative number, which is an ensemble estimate of relative process randomness, wherein larger ApEn values denote greater irregularity, as observed for ACTH in Cushing's disease, GH in acromegaly, and PRL in prolactinomas [7-9]. In the present analysis, we calculated ApEn with $r=20 \%$ of the $\mathrm{SD}$ of the individual time-series and $m=1$. This choice of parameters affords sensitive, valid and statistically wellreplicated ApEn metrics for assessing hormone time-series of this length. ApEn results are reported as absolute values or as the ratio of the absolute value to that of the mean of 1,000 randomly shuffled data series. Ratio values that approach 1.0 thus denote mean empirical randomness.

\section{Copulsatility}

Copulsatility between the GHRH and GH time-series was quantified by the hypergeometric (joint binomial) distribution [10]. This program calculates the probability that hormone pulses in time-series occur randomly. We used a time-window of $20 \mathrm{~min}$, with GHRH as leading hormone series. Because details of the secretion characteristics of GHRH are not well established, we estimated significant pulses in both time-series with Cluster, which is largely model-free [11].

\section{Clinical findings at diagnosis and initial treatment}

Case 1. A 50-year-old male was referred in 1982 because of recurrent kidney stones, hypercalciuria $(24 \mathrm{~h}$ urinary calcium excretion between $14.5 \mathrm{mmol}$ and $16.3 \mathrm{mmol}$, normal upper value $6 \mathrm{mmol} / 24 \mathrm{~h}$ ) and hypercalcaemia (serum Ca between $2.86 \mathrm{mmol} / \mathrm{l}$ and $2.95 \mathrm{mmol} / \mathrm{l}$, normal values between $2.25 \mathrm{mmol} / \mathrm{l}$ and $2.60 \mathrm{mmol} / \mathrm{l}$ ). The 
referring internist suspected the patient of having mild acromegaly, because of the coarse facial features. The diagnosis primary hyperparathyroidism was confirmed and the patient underwent parathyroid surgery, and two large adenomas were removed, after which the patient became normocalcaemic until now. The patient had noted increase in size of his feet and hands since several years, but otherwise he had no complaints. Glucose loading decreased $\mathrm{GH}$ from $12 \mathrm{mU} / \mathrm{l}$ to below $0.5 \mathrm{mU} / \mathrm{l}$ (normal value during glucose suppression is below $2.5 \mathrm{mU} / 1$ with RIA). Intravenous administration of $200 \mu \mathrm{g}$ TRH, however, increased GH from $3.5 \mathrm{mU} / 1$ to $58.0 \mathrm{mU} / 1$ and PRL increased from $7.0 \mu \mathrm{g} / \mathrm{l}$ to $13 \mu \mathrm{g} / \mathrm{l}$. CT scanning of the pituitary gland with the first generation CT-scanner (in 1983) did not show abnormalities, and CT scanning of the thorax and abdomen also failed to show the presence of a tumor. Because of progressive complaints of fatigue after cure for hyperparathyroidism and strong clinical suspicion of acromegaly, the patient underwent transsphenoidal pituitary exploration. At surgery a small suspect lesion was removed with part of the surrounding pituitary gland tissue. Histology of the lesion was compatible with somatotrope hyperplasia. After the patient had recovered from surgery, CT, MRI and arteriographic studies were repeated, and serum samples were sent to St. Bartholomew's Hospital, London, UK (Dr L.H. Rees) for GHRH measurement. The abdominal CT-scan showed a $4 \mathrm{~cm}$ mass in the middle section of the pancreas (Fig. 1) and the mass was also visible with selective arteriography of the superior mesenterial artery (Fig. 1). The fasting GHRH concentration amounted to $3,810 \mathrm{pg} / \mathrm{ml}$ (normal range $10-60 \mathrm{pg} / \mathrm{ml}$ ). GHRH concentration in the arterial supply to the tumor was $12,470 \mathrm{pg} / \mathrm{ml}$, and in the venous tumor outflow $31,120 \mathrm{pg} / \mathrm{ml}$, while in the systemic venous system the concentration was $8,900 \mathrm{pg} / \mathrm{ml}$. After removal of the pancreatic tumor, peripheral GHRH concentration decreased to normal values of $16-33 \mathrm{pg} / \mathrm{ml}$. In retrospect, the first abdominal CT-scan, 2 years before, already showed the pancreatic tumor with a similar size.

The patient was the index case of a large kindred affected by MEN-I syndrome. Later, a gene mutation was revealed in exon 2 of chromosome 11q13. During longterm follow-up GH and IGF-I concentrations remained normal.

Six years later, in 1988, the patient developed diabetes mellitus, initially treated with oral hypoglycemic drugs and with insulin from 1992 onwards. The patient also had mild bilateral nodular adrenal hyperplasia since 1988, with no evidence of growth during the last recent 10 years. No excess of adrenal (cortex and medulla) hormones or precursors was demonstrable during follow-up. During the last 3 years the plasma level of pancreatic polypeptide (PP) increased to $350 \mathrm{nmol} / \mathrm{l}$ (normal < $100 \mathrm{nmol} / \mathrm{l}$ ). Repeat CT
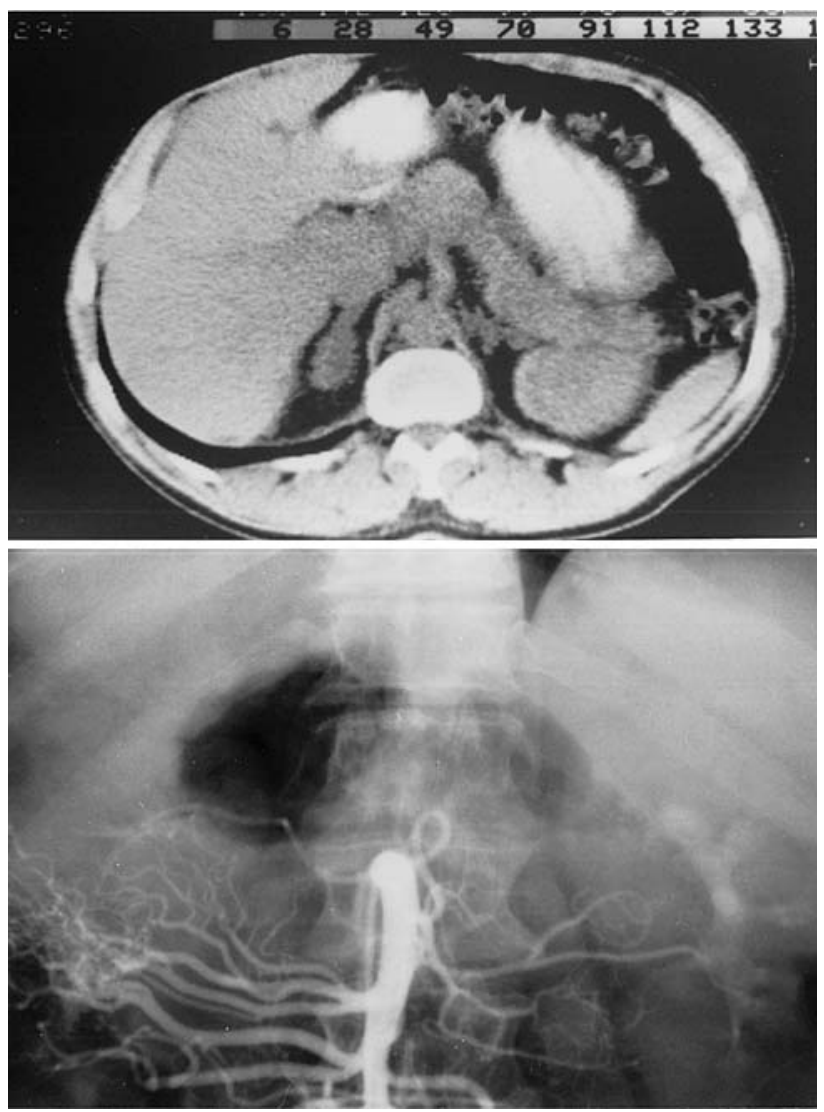

Fig. 1 Upper panel shows the abdominal CT at the level of the pancreas and the lower panel the selective arteriography of the superior mesenterial artery

and MRI scanning of the upper abdomen failed to reveal the presence of a pancreatic tumor thus far.

Random serum GH during follow-up ranged from $0.16 \mathrm{mU} / 1$ to $1.81 \mathrm{mU} / 1$ and IGF-I ranged from $12 \mathrm{nmol} / \mathrm{l}$ to $17 \mathrm{nmol} / \mathrm{l}$ from 1994 till now (see Fig. 2). All these values are perfectly normal for his age and gender. The last serum GHRH measurement in 2006 was normal with $32 \mathrm{pg} / \mathrm{ml}$.

Case 2. A 27-year-old acromegalic female patient was referred in 1993 to our center for octreotide treatment. She had a 5-year history of hyperhydrosis, fatigue, paraesthesias, and acral enlargement. After delivery of a healthy daughter in 1992 she had persisting amenorrhea and galactorrhea. Physical examination revealed mild, although characteristic features of acromegaly. Serum GH concentration was elevated at $99 \mathrm{mU} / 1$ and decreased insufficiently to $55 \mathrm{mU} / \mathrm{l}$ following oral glucose administration. IGF-I concentration amounted to $86 \mathrm{nmol} / \mathrm{l}$ (normal upper level for her age $32 \mathrm{nmol} / \mathrm{l}$ ) Thyroid and adrenal functions were normal, but prolactin concentration was elevated to $20 \mu \mathrm{g} / \mathrm{l}$ (normal upper limit for females $12 \mu \mathrm{g} / \mathrm{l}$ ). Other investigations performed (TRH test, GHRH test, and the i.v. octreotide test) are summarized in Fig. 3. TRH bolus 


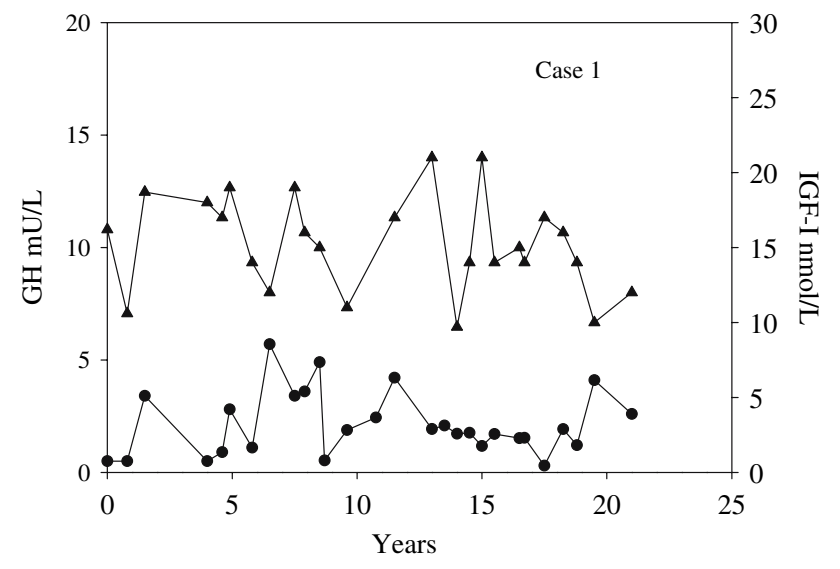

Fig. 2 Follow-up of GH and IGF-I concentration in patient 1 after removal of the pancreatic source of GHRH. Fasting serum GH concentrations are depicted as circles, and IGF-I as triangles

injection ( $200 \mu \mathrm{g}$ iv) caused a $\sim 8$-fold increase of GH and a 3.5-fold increase of PRL. Intravenous injection of $50 \mu \mathrm{g}$ GHRH (1-40) caused a decrease of GH while PRL concentrations remained unchanged. Octreotide (50 $\mu \mathrm{g}$ i.v.) caused a 98\% inhibition of serum GH but no effect on PRL. MRI scanning of the pituitary gland showed global enlargement without signs of an adenoma (Fig. 4). Further investigations revealed a large tumor in the right lower lobe of the lung (Fig. 5). The tumor and the pituitary gland were positive on ${ }^{111}$ In-labeled-octreotide scintigraphy (Fig. 6). The plasma GHRH concentration was increased 50 -fold by $2,519 \mathrm{pg} / \mathrm{ml}$ (normal values $<50 \mathrm{pg} / \mathrm{ml}$ ).

Under the diagnosis of ectopic GHRH-producing lung tumor (carcinoid) the patient underwent thoracotomy and the tumor was resected completely. The plasma GHRH disappearance profile after removal of the tumor is shown in Fig. 7, but the GHRH concentration did not normalize. GHRH concentrations in simultaneously withdrawn blood samples from the arterial supply to the tumor, venous tumor outflow and the systemic venous system were 1,890 , 2,180 , and $1,680 \mathrm{pg} / \mathrm{ml}$, respectively.

Two weeks after surgery, endocrine investigations revealed a persisting paradoxical increase (9-fold) of GH to TRH, insufficient GH suppression after oral glucose loading (52-16 mU/l) and a GH increase after GHRH injection. Octreotide caused a $98 \%$ decrease of $\mathrm{GH}$ from $41 \mathrm{mU} / \mathrm{l}$ to $0.9 \mathrm{mU} / \mathrm{l}$ (see Fig. 3). Treatment with octreotide was started in 1994, about 8 months after surgery, because of persisting elevated GHRH concentration (between $360 \mathrm{pg}$ /
Fig. 3 Dynamic GH (circles) and PRL (triangles) tests in two patients with a GHRH-secreting lung carcinoid before (closed symbols) and after surgery (open symbols). Note the GH increase after TRH $(200 \mu \mathrm{g})$ administration in both patients, the decrease in serum $\mathrm{GH}$ concentration in patient 2 after GHRH $(50 \mu \mathrm{g})$, and the moderate $\mathrm{GH}$ decrease after i.v. octreotide $(50 \mu \mathrm{g})$
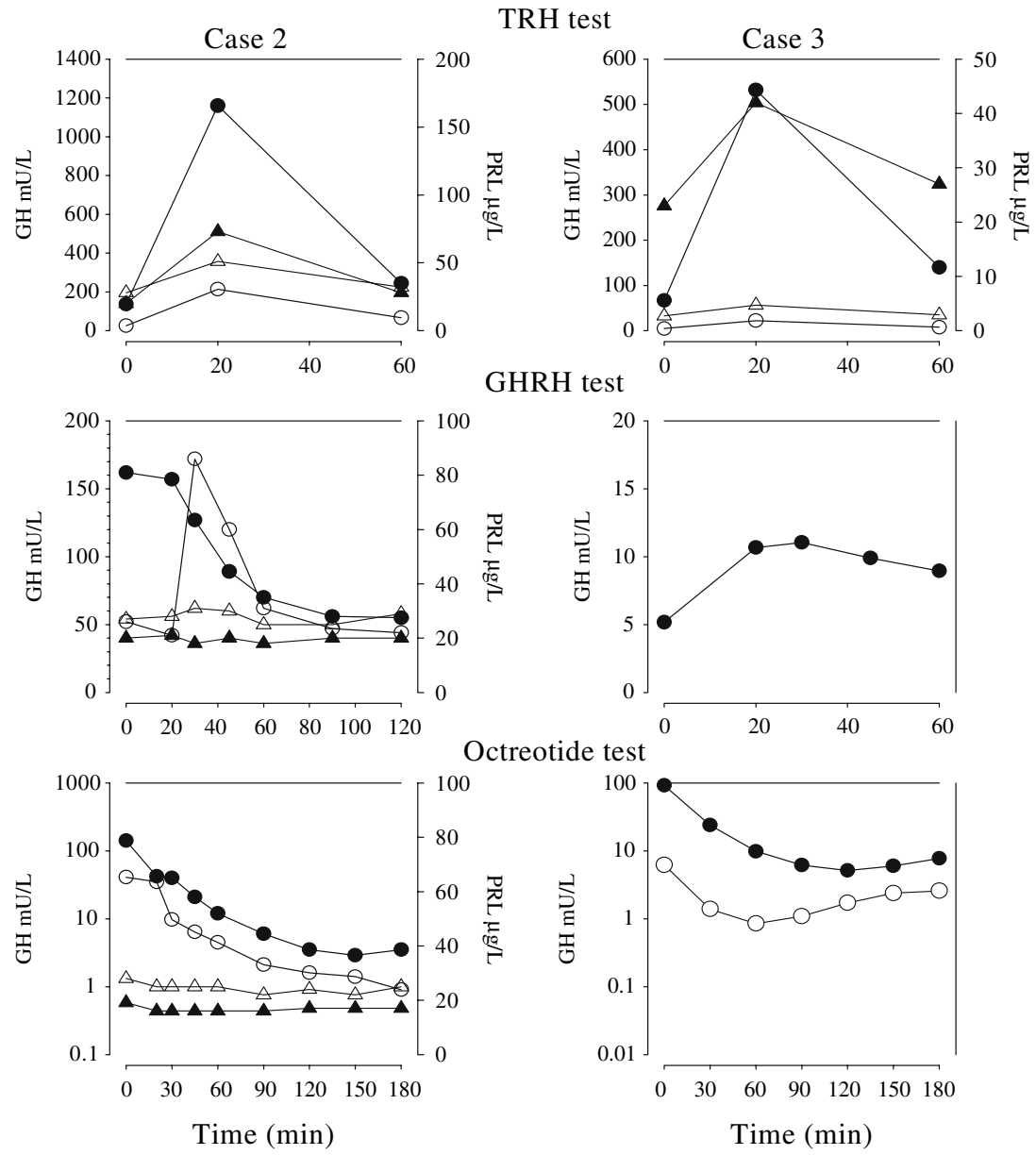
Fig. 4 MRI scans of the pituitary gland of patient 2 (left panel) and of patient 3 (right panel) before treatment
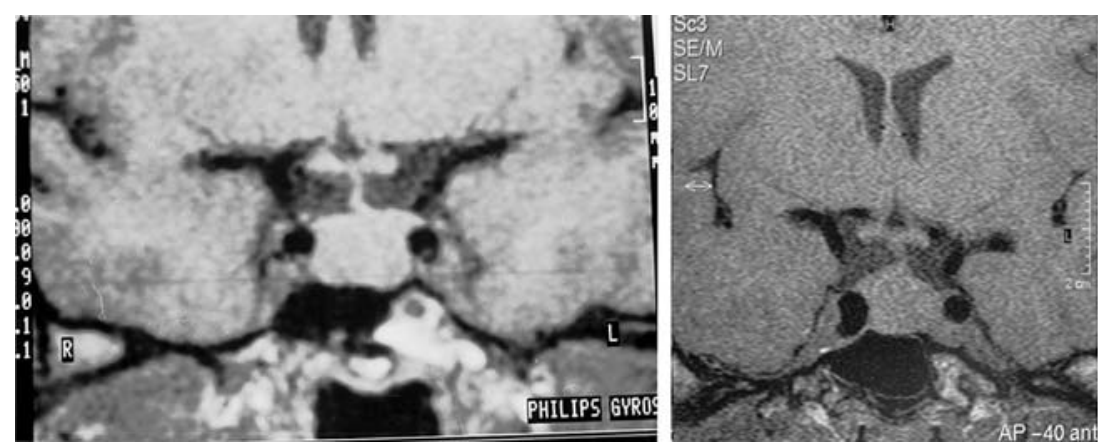

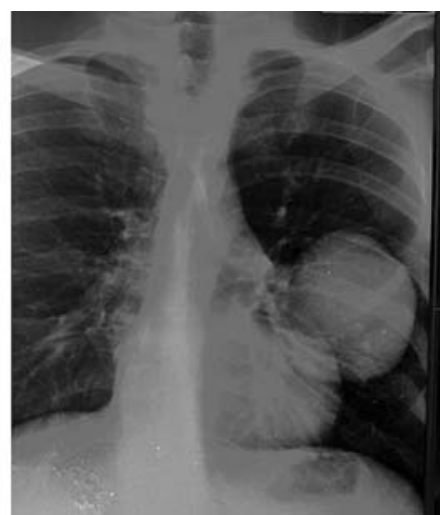

Fig. 5 Chest X-rays of patient 2 (left panel) and patient 3 (right panel), showing the large bronchial carcinoid
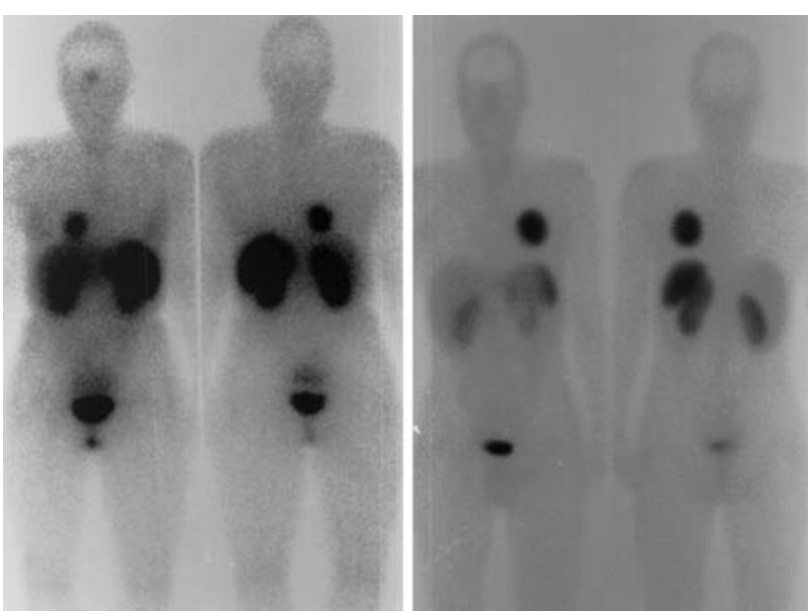

Fig. 6 Octreoscans of the patients 2 and 3. In the female patient (left panel) the tumor is seen in the right lower lobe of the lung and also the positive staining of the pituitary gland. The male patient (right panel) had a large tumor in the left lung, without pituitary staining

$\mathrm{ml}$ and $488 \mathrm{pg} / \mathrm{ml}$ ), increased $\mathrm{GH}(31-42 \mathrm{mU} / \mathrm{l})$, insufficient suppression by glucose loading (minimum $\mathrm{GH}$ concentration $9.13 \mathrm{mU} / \mathrm{l}$ ), an increased IGF-I concentration ( $40-43 \mathrm{nmol} / \mathrm{l}$ ), and lesions in the liver on repeat CT scans, suspect for metastases (one lesion in segments 2 and 8 , and two lesions in segment 7).

Case 3. A 27-year-old male was referred in 1997 to our center. He had a 9-year history of hyperhydrosis, acral enlargement and headaches. Examination revealed moderately

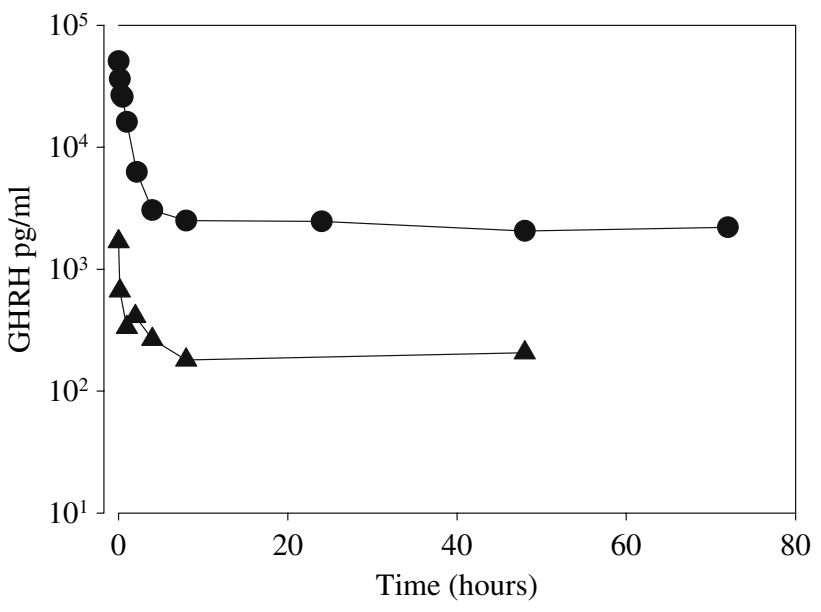

Fig. 7 Decrease in serum GHRH concentration in two patients before and immediately following removal of the lung tumor. Patient 2 is shown by triangles and patient 3 by circles. Note that the GHRH concentration is shown on a logarithmic scale. The GHRH concentration did not normalize in the patients after 2 and 3 days, respectively. Upper normal GHRH is $50 \mathrm{pg} / \mathrm{ml}$

advanced features of acromegaly. The circulating GH concentration was elevated at $110 \mathrm{mU} / \mathrm{l}$ and decreased insufficiently to $52 \mathrm{mU} / \mathrm{l}$ following glucose administration, and IGF-I was elevated to $63 \mathrm{nmol} / \mathrm{l}$ (normal upper level at this age $32 \mathrm{nmol} / \mathrm{l})$. Thyroid and adrenal functions were normal, but prolactin concentration was elevated to $21 \mu \mathrm{g} / \mathrm{l}$ (normal upper limit for males $6 \mu \mathrm{g} / \mathrm{l}$ ). Other investigations performed (TRH test and the i.v. octreotide test) are summarized in Fig. 3. TRH 
bolus injection (200 $\mu \mathrm{g}$ i.v.) caused a $\sim 8$-fold increase of $\mathrm{GH}$ and a 2-fold increase of PRL. Octreotide (50 $\mu \mathrm{g}$ i.v) caused a $94 \%$ inhibition of GH (Fig. 3). MRI scanning of the pituitary gland showed a macroadenoma II ${ }^{\mathrm{AE}}$ (Hardy classification, modified by Wilson [12, 13] see Fig. 4). He was treated for 6 months with sc octreotide (100 $\mu \mathrm{g}$ tid). The size of the adenoma decreased slightly, but because of the moderate clinical response to medical treatment and failure of normalization of GH and IGF-I, pituitary surgery was advised. One day before surgery a chest X-ray was taken, showing a large parahilar lesion (Fig. 5). CT scanning of this lesion was classified by the consultant pulmonologist and radiologist as a bronchial cyst and apparently unrelated to acromegaly. During pituitary surgery the adenoma was removed completely, but the neurosurgeon remarked that the consistency of the adenoma was firmer than normal. Since we suspected that the lung tumor was potentially a GHRH-producing source, postoperative investigations were focused on this possibility. After surgery, MRI scanning of the pituitary region did not show residual tumor, GH concentrations decreased considerably and PRL concentrations became normal. GH dynamic tests did not completely normalize: $\mathrm{GH}$ increased after TRH injection from $4.63 \mathrm{mU} / \mathrm{l}$ to $22.1 \mathrm{mU} / \mathrm{l}$ and after glucose loading $\mathrm{GH}$ decreased from $4.33 \mathrm{mU} / 1$ to $2.56 \mathrm{mU} / 1$ (normal value below $1 \mathrm{mU} / \mathrm{l}$ ). During an i.v. octreotide test $\mathrm{GH}$ decreased from $6.21 \mathrm{mU} / \mathrm{l}$ to $0.85 \mathrm{mU} / \mathrm{l}$, but treatment with this drug was not reinstituted. On ${ }^{111}$ In-labelled-octreotide scanning the tumor was positive (see Fig. 6).

Under the diagnosis of ectopic GHRH-producing lung tumor (carcinoid) the patient underwent thoracotomy and the tumor was removed completely. GHRH concentrations in the arterial supply to the tumor were $48,290 \mathrm{pg} / \mathrm{ml}$, in the venous outflow $94,000 \mathrm{pg} / \mathrm{ml}$ and in the systemic venous system $49,000 \mathrm{pg} / \mathrm{ml}$. After removal of the tumor GHRH concentrations remained slightly elevated, as shown in Fig. 7.

Histopathological studies

\section{Pituitary gland}

The removed part of the anterior pituitary gland of patient 1 consisted of hyperplastic cells, immunostaining positively for GH. The removed tissue of the third patient consisted of a mixture of hyperplasia and adenoma formation. The cells stained positively for both GH and PRL.

\section{GHRH-producing tumors}

Patient 1. The pancreatic tumor had a diameter of $5 \mathrm{~cm}$. Amorphous material was present between the cells, staining as amyloid. On electronmicroscopy, the cells contained neurosecretory granules with a diameter between $100 \mathrm{~nm}$ and $200 \mathrm{~nm}$. The tumor stained positively, but sparsely for somatostatin, insulin and glucagon and negatively for cytokeratine, vimentine, neurofilaments, desmine and GH. In the removed part of the pancreas three additional small adenomas with identical staining characteristics were present.

Patient 2. The diameter of the removed lung tumor was $5 \mathrm{~cm}$, and contained centrally calcified material. The cells were layered in nests, slightly polymorphic, but without mitotic figures. The tumor cells stained positively for keratine, vimentin, synaptophysin, SCCL (N-CAM), leu 7, and chromogranin and negatively for calcitonin, $\mathrm{GH}$, pancreatic polypeptide, insulin, prolactin, somatostatin, gastrin, ACTH, CEA, and neurofilaments.

Patient 3. The dimensions of the tumor were $8 \times 7 \times 7 \mathrm{~cm}^{3}$. The tumor showed clear proliferation of neuroendocrine cells with three mitotic figures per high power field, staining positively for NSE, CD56, and synaptophysin and negatively for keratine, chromogranin, serotonin, somatostatin, prolactin, insulin, glucagons, gastrin, ACTH, GH, and insulin.

\section{Somatostatin analog therapy}

After removal of the lung carcinoid, patients 2 and 3 received long-term treatment with octreotide, because GHRH was not normalized. Patient 2 received the medication via chronic sc infusion (300 $\mu \mathrm{g} / 24 \mathrm{~h})$ till the end of 1998 . Her complaints quickly disappeared and the menstrual cycle was restored. GH and IGF-I concentrations normalized and are detailed in the left panel of Fig. 9. The size of the pituitary gland decreased markedly (Fig. 8). PRL concentration also normalized from $15.2 \pm 0.2 \mu \mathrm{g} / \mathrm{l}$ to $6.8 \pm 0.2 \mu \mathrm{g} / \mathrm{l}$. From 1999 onwards the medication was changed to octreotide long-acting repeatable (Sandostatin LAR), $20 \mathrm{mg}$ in 4-weekly i.m. injections. Growth hormone and IGF-I concentrations remained unchanged (see Fig. 9). During chronic treatment with the short-acting octreotide formulation treatment was withheld several times for GHRH measurement. Invariably, the concentration was (slightly) elevated (range 116-363 ng/ml) so that in combination with the radiological suspicion for liver metastases, treatment is continued until now. During treatment with octreotide long-acting repeatable (Sandostatin LAR) GHRH concentration ranged from $63 \mathrm{ng} / \mathrm{ml}$ to $108 \mathrm{ng} / \mathrm{ml}$. Repeat CT scanning of the liver during the successive years demonstrated the stabilization of size and number of lesions until now.

After removal of the carcinoid tumor in patient 3, GHRH, GH, and IGF-I concentrations remained elevated, and therefore he was also treated with the long-acting repeatable octreotide (20 mg/4 weeks). GH and IGF-I concentrations are shown in Fig. 9, right panel, showing 


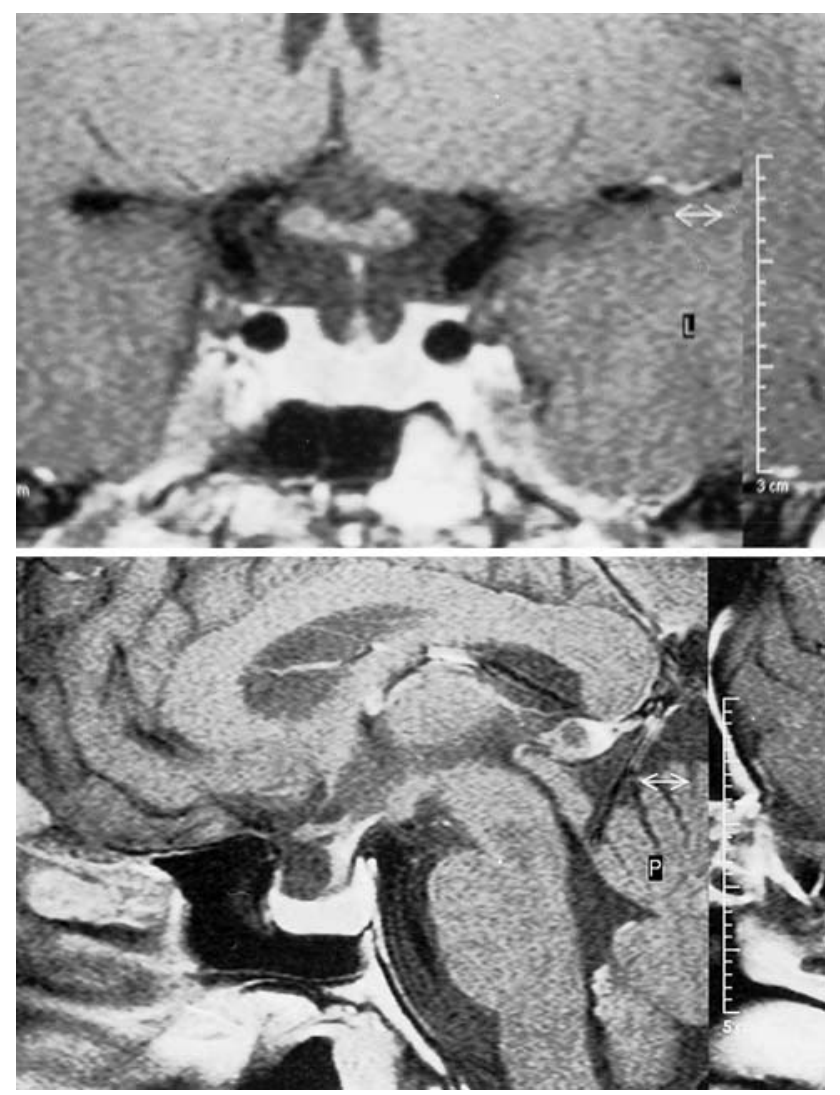

Fig. 8 MRI of the pituitary gland of patient 2 during therapy with octreotide. These pictures were taken after 12 months treatment with $300 \mu \mathrm{g}$ octreotide given as a continuous subcutaneous infusion

clinically normal values. Repeat investigations with CT, ${ }^{111}$ In-labeled octreotide and ${ }^{131}$ I-MIBG however, did not reveal suspect (liver) metastases. At the end of 2001, GHRH was elevated to $1,725 \mathrm{ng} / \mathrm{ml}$, so that thereafter the dose of Sandostatin was increased to $30 \mathrm{mg}$ at 4-weekly intervals, which normalized IGF-I concentrations. Last year the patient stopped medication. Subsequently, IGF-I

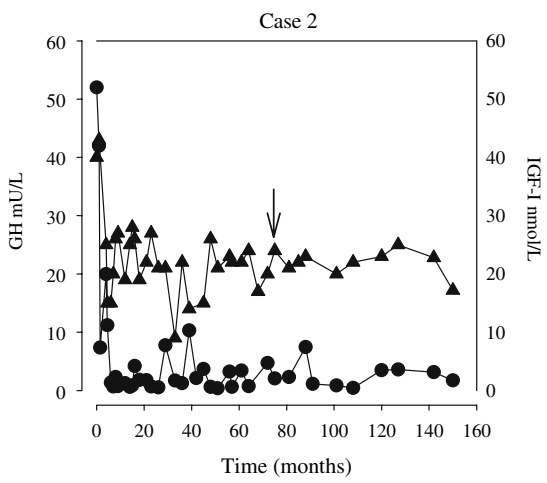

Fig. 9 GH (circles) and IGF-I (triangles) concentrations during longterm treatment with octreotide. Patient 3 received only the long-acting repeatable form, but patient 2 was treated initially with chronic sc levels increased, as shown in Fig. 9. GHRH concentration became larger than $2,000 \mathrm{pg} / \mathrm{ml}$. Detailed localizing studies with octreotide and $C T$ revealed a small metastasis in the superior anterior mediastinum for which surgery is scheduled.

\section{GH secretory profiles}

Detailed GH secretory profiles were obtained before removal of the GHRH-producing bronchial carcinoids (Fig. 10). The secretory patterns were irregular, showing increased burst frequency and increased basal concentrations. The GH secretory parameters as estimated by multiparameter deconvolution are listed in Table 1 with normal values obtained in healthy adults of comparable age. The distinct and persisting abnormality in both patients after removal of the carcinoid and while on octreotide treatment was the increased basal (nonpulsatile) GH secretion.

In addition, the secretory regularity was quantified with the approximate entropy statistic, ApEn. In patient 2, ApEn was 1.256 before removal of the carcinoid, and after surgery and under somatostatin analog treatment ApEn was still increased to 0.686 (median normal for women 0.400 , 95\% confidence interval 0.300-0.440). In patient 3 ApEn also remained abnormal: preoperative 1.256 and after surgery 0.687 , median normal for males $0.240,95 \%$ confidence interval $0.160-0.350$ (see Table 2). In addition, the serum GH profiles of two patients reported in literature were digitized and analyzed in a similar way $[14,15]$. The results of these analyses are also displayed in Table 1. In these male patients basal GH secretion was much higher than in our healthy controls and pulsatile secretion was augmented via increased pulse frequency and pulse amplitude. ApEn of GH secretion was 1.533 in Jaffe's patient and 1.248 in the patient reported by Vance (increased SD scores by 8- and 6-fold, respectively). ApEn for

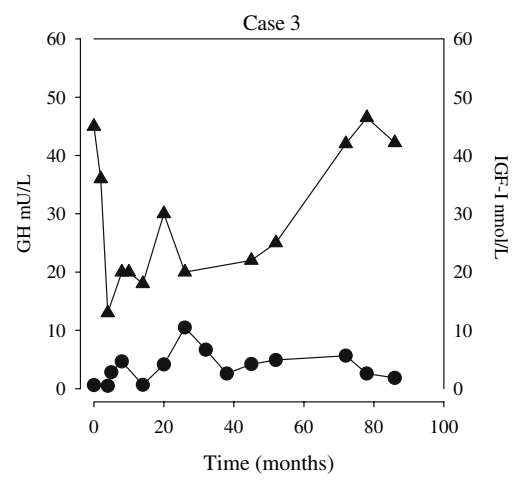

octreotide infusion. The time of change into the slow-release formulation is indicated by the arrow. Normal values for IGF-I for this age: $<32 \mathrm{nmol} / 1$. Normal value for random $\mathrm{GH}<5 \mathrm{mU} / \mathrm{l}$ 
Fig. 10 Serum GH

concentrations obtained by

$10 \mathrm{~min}$ blood sampling for $24 \mathrm{~h}$.

Patient 2 was studied before therapy and after surgical removal of the lung tumor. Note that $\mathrm{GH}$ concentration decreased more than 10 -fold and that the secretion pattern became more regular, but basal GH concentration remained slightly elevated. The left lower panel represent the profile of patient 3 after pituitary surgery, but before removal of the carcinoid tumor. Nadir values were clearly increased. After thoracic surgery and under octreotide treatment $\mathrm{GH}$ secretion pattern visually normalized
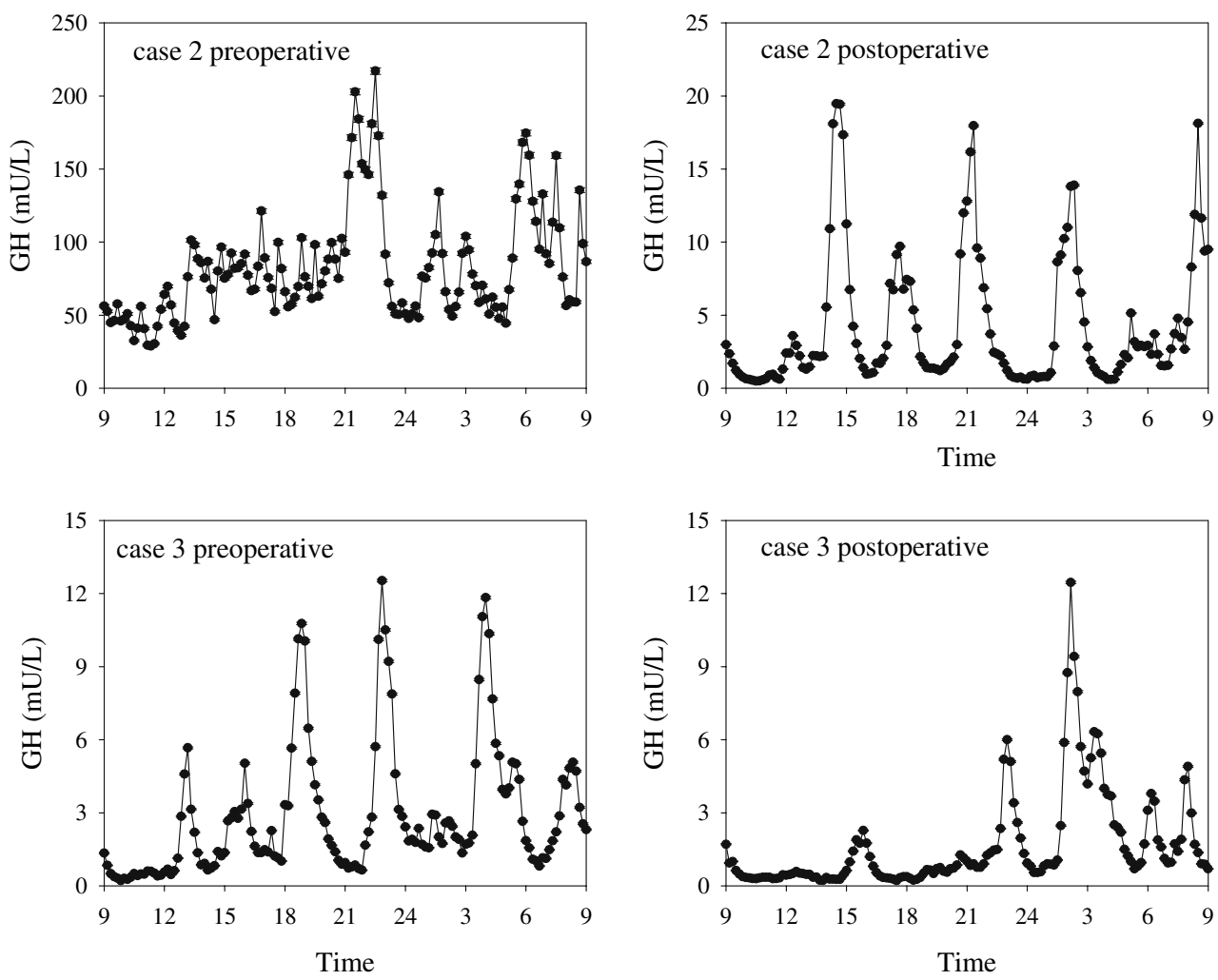

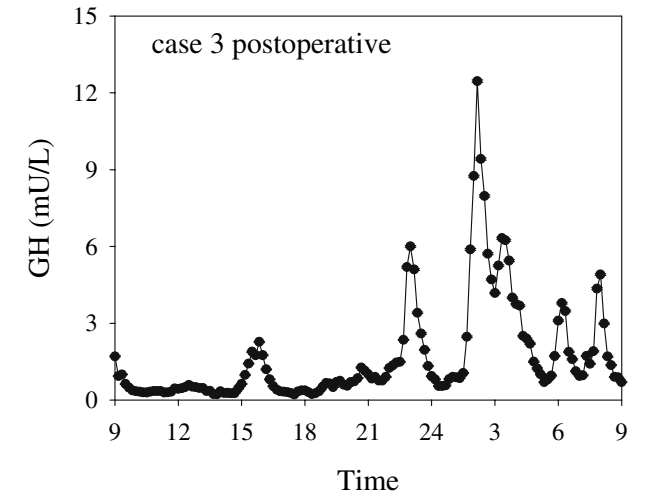

the serum GHRH-time series were 1.759 and 1.223, respectively. Copulsatility of the GH and GHRH hormone series was highly significant in both patients $(P<0.0001)$.

\section{Discussion}

In this study we described in detail the clinical and biochemical characteristics of three patients with ectopic extracranial GHRH secretion diagnosed in a series of about 200 acromegalics investigated and treated in our center during the last 25 years. The incidence in the present series agrees with that mentioned in literature [1, 16]. Faglia summarized the clinical findings of 39 reported acromegalic patients with proven ectopic GHRH secretion [17]. Subsequently, van den Bruel and colleagues [18] mentioned 52 reported patients in 1999, including their own patient and since then 14 other patients have been reported, bringing the total number reported to 66 patients [19-32]. From a conservative estimation of the total number of newly diagnosed acromegalic patients in Europe, Japan and the USA, it is evident that most patients with ectopic GHRH syndrome are either not reported or remain undiagnosed.

The criteria for demonstration of ectopic extracranial GHRH-induced acromegaly are summarized by Losa and von Werder [2], and include the presence of high circulating concentration GHRH by specific radioimmunoassays, the presence of GHRH in the tumor, the presence of mRNA for
GHRH by in situ hybridization and/or a significant arteriovenous gradient across the ectopic source. The second requirement to be fulfilled is the reversibility of acromegaly after complete removal of the ectopic-hormone producing tumor. All our patients met at least two criteria, although the tumors were not investigated for the presence of GHRH.

The clinical symptomatology in ectopic GHRH-induced acromegaly is not different from that of the primary pituitary adenomatous form. However, symptoms due to the underlying neoplasm or cosecretion of other substances by the tumor might suggest the ectopic origin of acromegaly [33]. Specific dynamical tests for GH excess do not allow classification with certainty in either category, although most patients with ectopic GHRH syndrome exhibit a paradoxical increase of GH after TRH and glucose (i.e. $>50 \%)$ and a blunted $\mathrm{GH}$ rise $(<100 \%)$ after exogenous GHRH injection [33]. In addition, most patients also exhibit a moderate increase in serum prolactin concentration, which regresses after removal of the ectopic GHRH source, supporting the notion that GHRH is directly responsible for the hyperprolactinemia, a finding also present in hGHRH-transgenic mice [34]. The patients reported here all exhibited GH increase after TRH, and two had mild hyperprolactinemia. After surgery, hyperprolactinemia normalized, but GH still increased after TRH administration, suggesting that GHRH was still being produced by tumor remnants or metastases in two patients (nos. 2 and 3). 


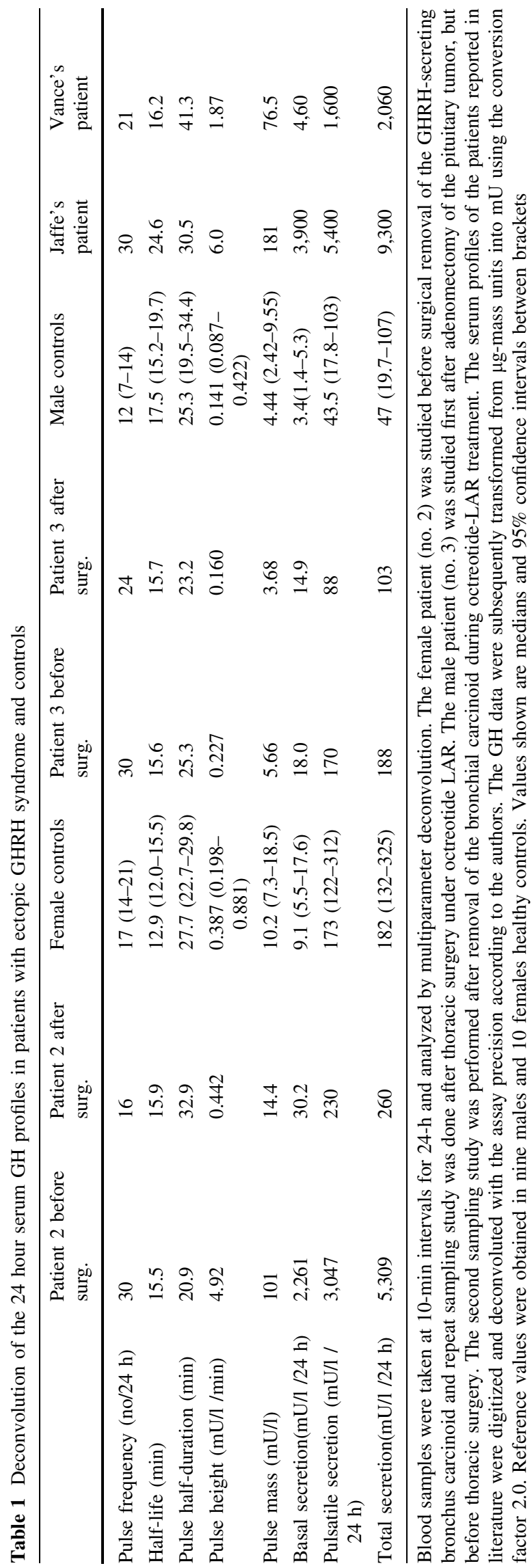

The most frequent source of ectopic GHRH is the bronchial carcinoid, followed by pancreatic islet tumors [17], as we also found in the present evaluation of our patient series. The pancreatic tumor in the first patient was found by CT-scanning and MRI. The large bronchial carcinoids were easily seen by chest X-ray examination, and showed uptake of radio-labeled octreotide, thus demonstrating in vivo the presence of somatostatin receptors. Although positive somatostatin receptor-scintigraphy is usually found in carcinoids in general, its demonstration in ectopic GHRH tumors is limited. Nevertheless, this examination could be particularly useful in the diagnostic phase of patients with suspected, but not yet proven, ectopic GHRH secretion.

Histological investigation of surgically removed pituitary tissue revealed pituitary hyperplasia in most cases (i.e. with an intact reticulin fiber network), but in other patients adenomatous transformation can be found [35]. Indeed, the histological findings in hGHRH transgenic mice resemble those in the human: in young animals diffuse hyperplasia was found, while those of older mice showed adenomas $[34,36]$. The pathological changes in the pituitary gland are the result of GHRH per se and not of $\mathrm{GH}$, since hyperplasia and tumor formation still occur in the absence of GH signaling [37]. A hypothalamic GHRH-producing tumor (gangliocytoma) is generally associated with a pituitary adenoma rather than with pituitary hyperplasia and is attributed to a much higher (assumed) local (pituitary) concentration of GHRH or the presence of other growth stimulating factors [38]. In addition, the combination of an intrasellar GHRH-containing gangliocytoma and a somatotropinoma has been described in rare patients [39, 40]. In two of our patients pituitary histology was available: one patient (no. 1) showed hyperplasia in the absence of an enlarged gland, while histology in the other patient (no. 3) showed a mixture of hyperplasia and adenomatous transformation.

Neuroimaging studies of the pituitary gland are variable: in about half of the patients no tumor or a slight enlargement of the sella is detected, while in other patients intrasellar adenomas or macroadenomas with suprasellar extension are found [18]. The CT-scan of patient 1 was normal and MRI scanning in patient 2 showed diffuse enlargement of the pituitary gland without a clear adenoma and with diffuse uptake of gadolinium DTPA. In patient 3 asymmetric enlargement was present, suggestive of a macroadenoma, but uptake of gadolinium DTPA throughout the whole pituitary gland was diffuse, illustrating the variability of imaging results. Although the pituitary MRI studies in the ectopic GHRH syndrome are non-specific, in the absence of a clear adenoma, ectopic GHRH secretion should be considered and appropriate investigations installed to prevent unnecessary pituitary surgery. On the 
Table 2 Approximate entropy of GH secretion in ectopic GHRH syndrome

\begin{tabular}{lllr}
\hline Patient & $\begin{array}{l}\text { Before removal of the } \\
\text { ectopic GHRH source }\end{array}$ & $\begin{array}{l}\text { After surgery and during } \\
\text { octreotide treatment }\end{array}$ & $\begin{array}{l}\text { Reference values, } \\
\text { Median and 95\% CI }\end{array}$ \\
\hline No. 2 (female) & 1.256 & 0.686 & $0.400(0.300-0.440)$ \\
No. 3 (male) & 0.842 & 0.561 & $0.240(0.166-0.350)$ \\
Jaffe's patient & 1.533 & & $0.240(0.166-0.350)$ \\
Vance's patient & 1.248 & & $0.240(0.166-0.350)$ \\
\hline
\end{tabular}

Calculations were performed on GH data series consisting of 145 samples obtained at 10 min intervals during $24 \mathrm{~h}$. Normal values were derived from nine males and 10 females healthy controls

other hand, primary medical treatment for acromegaly in these patients might obscure the real cause.

Carcinoids, especially of the lung and gastrointestinal tract constitute about two-thirds of all cases reported so far, followed by pancreatic islet cell tumors [17, 33]. Metastases of carcinoid tumors were present in about $30 \%$, a frequency similar to lung carcinoids in general [35]. Two of our patients had a large primary lung carcinoid, but had no histological proven metastases. Because serum GHRH concentration did not normalize after removal of the GHRH source we assumed (liver) metastases.

Immunochemistry of the GHRH-secreting tumors has regularly demonstrated cosecretion of other hormones, including gastrin, gastrin-releasing peptide, calcitonin, pancreatic polypeptide, VIP, glucagon, insulin, and somatostatin, pointing to the multihormonal nature of these tumors. Particularly, cosecretion of somatostatin may modify the clinical picture and severity [31-44].

Only few patients with a GHRH-producing pancreatic islet cell tumor and with MEN I syndrome have been described [41, 43, 44]. In agreement with our patient 1 , they had multiple tumors; however, the pancreatic tumors in our patient showed an identical immunohistochemical profile in contrast with the other reported patients. The tumor stained positively for somatostatin, which might explain the only moderately increased GH concentration and possibly also the normal GH response to glucose loading, as alluded to above. In the follow-up of more than 20 years, no recurrence of acromegaly occurred, but the (modest) increase of pancreatic polypeptide could point to the development of a new pancreatic adenoma.

GH secretory characteristics of two patients were investigated before removal of the GHRH source. We established that pulsatile and non-pulsatile (basal) secretion, pulse frequency and secretory regularity (ApEn) were comparable to untreated acromegalic patients with primary pituitary adenomas $[8,45]$. Because of the highly significant copulsatility of GHRH and GH in two other patients reported in literature, it is reasonable to postulate that pulsatile $\mathrm{GH}$ secretion in these patients was generated via episodic GHRH secretion of the primary tumor, while in patients with a pituitary GH-secreting adenoma pulsatile secretion is probably a tumorous feature [8].

Approximate entropy calculations of serum GHRH profiles disclosed high values, suggesting highly irregular secretion, a feature common with many other hormonesecreting tumors [7-9]. It is reasonable to assume that the irregular secretion of $\mathrm{GH}$ in the four patients who were investigated till now was mainly the result of the irregular GHRH-input signal, and analogous to the irregular cortisol secretion driven by ACTH in pituitary-dependent Cushing's syndrome [7, 46]. Nevertheless, part of the irregularity of $\mathrm{GH}$ secretion might also be due to increased GHRH per se, since GHRH infusion in healthy subjects augments irregular GH secretion [47]. After surgery and on effective octreotide therapy aimed at normalizing IGF-I, $\mathrm{GH}$ secretion became almost normal. GH secretion remained however irregular (increased ApEn), notwithstanding the increased feedback signal of octreotide, and the diminished forward input signal of GHRH by octreotide [48, 49]. Similarly, octreotide treatment in (classical) acromegaly represses secretory-burst mass and non-pulsatile secretion but does not restore event frequency or orderly GH secretion [50]. Collectively, these results suggest that even a modestly increased GHRH concentration can maintain irregular GH secretion in ectopic acromegaly.

\section{Therapy}

Surgical removal of the GHRH source is obviously the treatment of choice and results in the resolution of acromegaly when no metastases are present, as we observed in the first patient with more than 20 year follow-up. In the presence of metastases octreotide treatment is often, but not invariable, successful in suppressing GH and GHRH, because of its dual action on the pituitary gland and the GHRH-secreting tumor [51]. Most published reports concerned subcutaneously administered octreotide mostly by three daily injections and in a minority by chronic subcutaneous infusion $[48,52]$ and summarized by van den Bruel et al. [18]. In the majority of patients $\mathrm{GH}$ decreased substantially, but IGF-I remained elevated in eight of 13 
patients in whom IGF-I was measured. The serum concentration of GHRH generally remained elevated [2], as we found in patient 3 . Publications of treatment results with the slow release formulation of octreotide and lanreotide are scarce and follow-up short-term. We could find only four cases in literature: three patients were treated with lanreotide and one with octreotide-long acting repeatable (octreotide LAR) [19, 21, 24, 25]. In the present study we reported the long-term effect of octreotide-LAR treatment in two patients, which resulted in suppressed GH secretion and normalized IGF-I concentration in both patients, but with still slightly elevated GHRH concentrations, as long as the patients continued suppressive therapy. The latter finding is indeed often mentioned in other reports as well, as discussed above. Other treatment modalities applied in single cases are the use of a GHRH-receptor antagonist and chemotherapy in a patient with severely metastasized disease $[15,53]$.

During octreotide treatment no visible growth of (eventual) metastases was noted for many years with highsensitivity liver CT scanning and CT scanning of the thorax in our patients, which suggests that in selected cases octreotide can inhibit growth of metastases from a carcinoid tumor. In addition, pituitary hyperplasia, the likely cause of the preoperative enlargement in patient 2, slowly disappeared completely, as previously described in other patients under medical therapy or after complete surgical removal of the GHRH source [27, 54]. Nevertheless, in patient 3 GHRH levels increased slowly, suggesting growing metastasis under octreotide restraint. Recently, we could localize a suspect lesion in the anterior mediastinum.

GHRH and its receptor are normally present in several organs, including the ovary and testis, playing a role in the regulation of steroidogenesis, and the pancreas [55-57]. It has been found that some GHRH-producing carcinoids also express GHRH-receptors, which may stimulate tumor growth via an autocrine mechanism [22]. Particularly interesting was the description of a single acromegalic patient whose large pituitary adenoma co-expressed GHRH-receptor and GHRH together with a 100-fold increased plasma GHRH concentration. After pituitary adenomectomy plasma GHRH normalized. It is likely that the high local concentration of GHRH contributed to the growth of the adenoma [58].

GHRH and its receptor are also expressed in cancers of the breast, ovary, and endometrium and small-cell lung cancer, and may function as a paracrine/autocrine growth factor in regulating local IGF-I and/or IGF-II secretion. Other studies have shown that GHRH receptor-antagonists inhibit the growth of colorectal, prostatic, mammary, lung, and pancreatic cancers, partly by direct suppression of IGFI and IGF-II production, or acting directly without influencing these growth factors [59-63]. When more potent
GHRH-receptor antagonists will become available for clinical application patients with advanced disease may benefit from this new approach, because they respond at best to somatostatin analogue therapy by suppressing $\mathrm{GH}$ secretion and partly that of GHRH, but the tumor and metastases will usually grow with fatal outcome.

\section{References}

1. Thorner MO, Frohman LA, Leong DA, Thominet J, Downs T, Hellmann P, Chitwood J, Vaughan JM, Vale W (1984) Extrahypothalamic growth-hormone-releasing-factor (GRF) secretion is a rare cause of acromegaly: plasma GRF levels in 177 acromegalic patients. J Clin Endocrinol Metab 59:846-849

2. Losa M, von Werder K (1997) Pathophysiology and clinical aspects of the ectopic GH-releasing hormone syndrome. Clin Endocrinol 47:123-135

3. Veldhuis JD, Carlson ML, Johnson ML (1987) The pituitary gland secretes in bursts: appraising the nature of glandular secretory impulses by simultaneous multiple-parameter deconvolution of plasma hormone concentrations. Proc Natl Acad Sci USA 84:7686-7690

4. Friend K, Iranmanesh A, Veldhuis JD (1996) The orderliness of growth hormone $(\mathrm{GH})$ release process and the mean mass of $\mathrm{GH}$ secreted per burst are highly conserved in individual men on successive days. J Clin Endocrinol Metab 81:3746-3753

5. Pincus SM (1991) Approximate entropy as a measure of system complexity. Proc Natl Acad Sci USA 88:2297-2301

6. Pincus SM, Goldberger AL (1994) Physiological time-series analysis: what does regularity quantifies? Am J Physiol 266:H1643-H1656

7. Van den Berg, Pincus SM, Veldhuis JD, Frölich M, Roelfsema F (1997) Greater disorderliness of ACTH and cortisol release accompanies pituitary-dependent Cushing's disease. Eur J Endocrinol 136:394-400

8. Van den Berg G, Pincus SM, Frölich M, Veldhuis JD, Roelfsema F (1998) Reduced disorderliness of growth hormone release in biochemically inactive acromegaly after pituitary surgery. Eur J Endocrinol 138:164-169

9. Groote Veldman R, van den Berg G, Pincus SM, Frolich M, Veldhuis JD, Roelfsema F (1999) Increased episodic release and disorderliness of prolactin secretion in both micro- and macroprolactinomas. Eur J Endocrinol 140:192-200

10. Veldhuis JD, Johnson ML (1991) Analysis of copulsatility of anterior pituitary hormones. J Clin Endocrinol Metab 73:569-576

11. Veldhuis JD, Johnson ML (1986) Cluster analysis, a simple, versatile, and robust algorithm for endocrine pulse detection. Am J Physiol 250:E486-E493

12. Hardy J, Vezina JL (1976) Transsphenoidal neurosurgery of intracranial neoplasm. In: Thompson RA, Green JR (eds) Advances in neurosurgery, vol 15. Raven Press, New York, pp 261-275

13. Wilson CB (1979) Neurosurgical management of large and invasive pituitary tumors. In: Tindall GT, Collins WF (eds) Clinical management of pituitary disorders. Raven Press, New York, pp 335-342

14. Vance ML, Kaiser DL, Evans WS, Furlanetto R, Vale W, Rivier J, Thorner MO (1985) Pulsatile growth hormone secretion in normal man during a continuous 14-hour infusion of growth hormone releasing factor (1-40). J Clin Invest 75:1584-1590

15. Jaffe CA, DeMott-Friberg R, Frohman LA, Barkan AL (1997) Suppression of growth hormone $(\mathrm{GH})$ hypersecretion due to ectopic GH-releasing hormone (GHRH) by a selective GHRH antagonist. J Clin Endocrinol Metab 82:634-637 
16. Penny ES, Penman E, Price J, Sopwith AM, Wass JA, Lytras N, Besser GM (1984) Circulating growth hormone-releasing factor concentrations in normal subjects and in patients with acromegaly. Brit Med J 289:453-455

17. Faglia G, Arosio M, Bazzoni N (1992) Ectopic acromegaly. Endocrinol Metab Clin North Am 21:575-595

18. Van den Bruel A, Fevery J, van Dorpe J, Hofland L, Bouillon R (1999) Hormonal and volumetric long term control of a growth hormone-releasing hormone-producing carcinoid tumor. J Clin Endocrinol Metab 84:3162-3169

19. Jansson J-O, Svensson J, Bengtsson B-A, Frohman LA, Ahlman H, Wangberg B, Nilsson O, Nilsson M (1998) Acromegaly and Cushing's syndrome due to ectopic production of GHRH and ACTH by a thymic carcinoid tumour: in vitro responses to GHRH and GHRP-6. Clin Endocrinol 48:243-250

20. Drange MR, Melmed S (1998) Long-acting lanreotide induces clinical and biochemical remission of acromegaly caused by disseminated growth hormone/releasing hormone/secreting carcinoid. J Clin Endocrinol Metab 83:3104-3109

21. Krassowski J, Zgliczynski W, Jeske W, Zgliczynski S (1999) Comment on long-acting lanreotide inducing clinical and biochemical remission of acromegaly caused by disseminated GHRH secreting carcinoid. J Clin Endocrinol Metab 84:17611762

22. Othman NH, Ezzat S, Kovacs K, Horvath E, Poulin E, Smyth HS, Asa SL (2001) Growth hormone-releasing hormone(GHRH) and GHRH receptor(GHRH-R) isoform expression in ectopic acromegaly. Clin Endocrinol 55:135-140

23. Furrer J, Hattenschwiler A, Komminoth P, Pfammatter T, Wiesli P (2001) Carcinoid syndrome, acromegaly, and hypoglycaemia due to an insulin-secreting neuroendocrine tumor of the liver. J Clin Endocrinol Metab 86:2227-2230

24. Altstadt TJ, Azzarelli B, Bevering C, Edmuondson J, Nelson PB (2002) Acromegaly caused by a growth hormone-releasing hormone-secreting carcinoid: case report. Neurosurgery 50:13561359

25. Boix E, Pico A, Pinedo R, Aranda I, Kovacs K (2002) Ectopic growth hormone-releasing hormone secretion by thymic carcinoid tumour. Clin Endocrinol 57:131-134

26. Lorcy Y, Perdu S, Sevray B, Cohen R (2002) Acromegaly due to ectopic GHRH secretion by a bronchial carcinoid tumor: a case report. Ann Endocrinol (Paris) 63:536-539

27. Bolanowski M, Schopol J, Marcianak M, Rseszutko M, Zatonska K, Daroszewski J, Milewicz A, Malczewska J, Badowski R (2002) Acromegaly due to GHRH-secreting large bronchial carcinoid. Complete recovery following tumor surgery. Exp Clin Endocrinol Diabetes 110:188-192

28. Osella G, Orlandi F, Caraci P, Ventura M, Deandreis D, Papotti M, Bongiovanni M, Angeli A, Terzolo M (2003) Acromegaly due to ectopic secretion of GHRH by bronchial carcinoid in a patient with empty sella. J Endocrinol Invest 26:163-169

29. Athanassiadi K, Exarchos D, Tsagarakis S, Bellenis I (2004) Acromegaly caused by ectopic growth hormone-releasing hormone secretion by a carcinoid bronchial tumor: a rare entity. $\mathbf{J}$ Thorac Cardiovasc Surg 128:631-632

30. Agha FL, Downey P, Keeling P, Leen E, Sreenan S (2004) Acromegaly secondary to growth hormone releasing hormone secretion. Ir J Med Sci 173:215-216

31. Zatelli MC, Maffei P, Piccin D, Martini C, Rea F, Rubello D, Margatti A, Culler MD, Sicolo N, degli Uberti EC (2005) Somatostatin analogs in vitro effects in a growth hormonereleasing-hormone-secreting bronchial carcinoid. J Clin Endocrinol Metab 90:2104-2109

32. Nasr C, Mason A, Mayberg M, Staugaitis SM, Asa SL (2006) Acromegaly and somatotroph hyperplasia with adenomatous transformation due to pituitary metastasis of a GHRH-secreting pulmonary endocrine carcinoma. J Clin Endocrinol Metab 91:4776-4780

33. Losa M, Schopohl J, von Werder K (1993) Ectopic secretion of growth hormone-releasing hormone in man. J Endocrinol Invest $16: 69-81$

34. Stefaneanu L, Kovacs K, Horvath E, Asa SL, Losinski LE, Billestrup N, Price J, Vale W (1989) Adenohypophyseal changes in mice transgenic for human growth hormone-releasing hormone factor: a histological, immunocytochemical, and electron microscopic investigation. Endocrinology 125:2710-2718

35. Sano T, Asa SL, Kovacs K (1988) Growth hormone-releasing hormone-producing tumors: clinical, biochemical and pathological manifestations. Endocr Rev 9:357-373

36. Asa SL, Kovacs K, Stefaneanu L, Horvarth E, Billestrup N, Gonzales Manchon G, Vale W (1990) Pituitary mammosomatotroph adenomas develop in old mice transgenic for growth hormone-releasing hormone. Proc Soc Exp Biol Med 193:232-235

37. Kineman RD, Teixeira LT, Amargo GV, Coschigano KT, Kopchik JJ, Frohman LA (2001) The effect of GHRH on somatotrope hyperplasia and tumor formation in the presence and absence of GH signalling. Endocrinology 142:3764-3773

38. Asa SL, Scheithauer BW, Bilbao JM, Horvath E, Ryan N, Kovacs K, Randall RV, Laws ER Jr, Singer W, Linfoot JA (1984) A case for hypothalamic acromegaly: a clinicopathological study of six patients with hypothalamic gangliocytomas producing growth hormone-releasing factor. J Clin Endocrinol Metab 58:796-803

39. Morikawa M, Tamaki N, Kokunai T, Imai Y (1997) Intrasellar pituitary gangliocyto-adenoma presenting with acromegaly: a case report. Neurosurgery 40:611-614

40. Luna V, Morales F, Luengo LM, Sanz A, Diaz J (2001) Pituitary gangliocytoma-adenoma presenting with acromegaly: response to treatment. Arch Intern Med 161:1010-1011

41. Berger G, Trouillas J, Bloch B, Sassolas G, Berger F, Partenski C, Chayvialle J-A, Brazeau P, Claustrat B, Lesbros F, Girod C (1984) Multihormonal carcinoid tumor of the pancreas secreting growth hormone-releasing factor as a cause of acromegaly. Cancer 54:2097-2108

42. Chadenas D, Pinsard D, Melliere D, Trouillas J, Zafrani ES, Pradayrol L, Sassolas G, Li Y, Girod C, Aumaitre J (1985) Tumeur pancréatique endocrine sécrétant de la somatostatine et de la somatocrine. La Presse Med 14:2129-2134

43. Sano T, Yamasaki R, Saito H, Hirose T, Kudo E, Kameyama K, Hiraishi K, Saito S, Hizawa K (1987) Growth hormone-releasing hormone (GHRH)-secreting pancreatic tumor in a patient with multiple endocrine neoplasia type I. Am J Surg Pathol 11:810-819

44. Ramsay JA, Kovacs K, Asa SL, Pike MJ, Thorner MO (1988) Reversible sellar enlargement due to growth hormone-releasing hormone production by pancreatic endocrine tumors in an acromegalic patient with multiple endocrine neoplasia type I syndrome. Cancer 62:445-450

45. Hartman ML, Pincus SM, Johnson ML, Matthews DH, Faunt LM, Vance ML, Thorner MO, Veldhuis JD (1994) Enhanced basal and disorderly growth hormone secretion distinguishes acromegalic from normal pulsatile growth hormone release. J Clin Invest 94:1277-1288

46. Roelfsema F, Pincus SM, Veldhuis JD (1998) Patients with Cushing's disease secrete adrenocorticotropin and cortisol jointly more asynchronously than healthy subjects. J Clin Endocrinol Metab 83:688-692

47. Evans WS, Anderson SM, Hull LT, Azimi PP, Bowers CY, Veldhuis JD (2001) Continuous 24-hour intravenous infusion of recombinant human growth hormone $(\mathrm{GH})$-releasing hormone(1-44)-amide augments pulsatile, entropic, and daily rhythmic $\mathrm{GH}$ secretion in postmenopausal women equally in the estrogenwithdrawn and estrogen-supplemented states. J Clin Endocrinol Metab 86:700-712 
48. Veldhuis JD, Straume M, Iranmanesh A, Mulligan T, Jaffe C, Barkan A, Johnson ML, Pincus S (2001) Secretory process regularity monitors neuroendocrine feedback and feedforward signalling strength in humans. Am J Physiol Regul Integr Comp Physiol 280:R721-R729

49. Veldhuis JD, Johnson ML, Veldhuis OL, Straume M, Pincus SM (2001) Impact of pulsatility on the ensemble orderliness (approximate entropy) of neurohormone secretion. Am J Physiol Regul Integr Comp Physiol 281:R1975-R1985

50. Biermasz NR, Pereira AM, Frolich M, Romijn JA, Veldhuis JD, Roelfsema F (2004) Octreotide represses secretory-burst mass and nonpulsatile secretion but does not restore event frequency or orderly GH secretion in acromegaly. Am J Physiol Endocrinol Metab 286:E1-E6

51. Moller DE, Moses AC, Jones K, Thorner MO, Vance ML (1989) Octreotide suppresses both growth hormone $(\mathrm{GH})$ and $\mathrm{GH}$ releasing-hormone $(\mathrm{GHRH})$ in acromegaly due to ectopic GHRH secretion. J Clin Endocrinol Metab 68:499-504

52. Levebre S, De Paepe L, Abs R, Rahier J, Selvais P, Maiter D (1995) Subcutaneous octreotide treatment of a growth hormonereleasing hormone-secreting bronchial carcinoid: superiority of continuous versus intermittent administration to control hormonal secretion. Eur J Endocrinol 133:320-324

53. Harris PE, Bouloux PM, Wass JA, Besser GM (1990) Successful treatment by chemotherapy for acromegaly associated with ectopic growth hormone-releasing hormone secretion from a carcinoid tumour. Clin Endocrinol 32:315-321

54. Wilson DR, Hoffman AR (1986) Reduction of pituitary size by the somatostatin analogue SMS 201-995 in a patient with an islet cell tumour secreting growth hormone releasing factor. Acta Endocrinol 113:23-28

55. Leung PC, Steele GL (1992) Intracellular signalling in the gonads. Endocr Rev 13:476-498

56. Frohman LA, Down TR, Kashio Y, Brinster RL (1990) Tissue distribution and molecular heterogeneity of human growth hormone-releasing factor in the transgenic mouse. Endocrinology 127:2149-2156

57. Berry SA, Srivastava CH, Rubin LR, Phipps WR, Pescovitz OH (1992) Growth hormone releasing hormone-like messenger ribonucleic acid and immunoreactive peptide are present in human testis and placenta. J Clin Endocrinol Metab 75:281-284

58. Matsuno A, Katakami H, Sanno N, Ogino Y, Osamura RY, Matsukura S, Shimizu N, Nagashima T (1999) Pituitary somatotroph adenoma producing growth hormone $(\mathrm{GH})$-releasing hormone $(\mathrm{GHRH})$ with an elevated plasma GHRH concentration: a model case for autocrine and paracrine regulation of $\mathrm{GH}$ secretion by GHRH. J Clin Endocrinol Metab 84:3241-3247

59. Kahan Z, Arencibia JM, Czernus VJ, Groot K, Kinema RD, Robinson WR (1999) Expression of growth hormone-releasing hormone (GH-RH) messenger ribonucleic acid, the presence of biologically active GH-RH in human breast, endometrial, and ovarian cancers. J Clin Endocrinol Metab 84:582-589

60. Doga M, Bonadonna S, Burattin A, Giustina A (2001) Ectopic secretion of growth hormone-releasing hormone (GHRH) in neuroendocrine tumors: relevant clinical aspects. Ann Oncology 12:S89-S94

61. Chatzistamou I, Schally AV, Pafiti A, Klaris H, Koutselini H (2002) Expression of growth hormone releasing hormone in human primary endometrial carcinomas. Eur J Endocrinol 147:381386

62. Kiaris H, Schally AV, Varga JL, Groot K, Armatis P (1999) Growth hormone-releasing hormone: an autocrine growth factor for small cell lung carcinoma. Proc Natl Acad Sci USA 96:14894-14898

63. Kahan Z, Arencibia JM, Czernus VJ, Groot K, Kinema RD, Robinson WR (1999) Expression of growth hormone-releasing hormone $(\mathrm{GH}-\mathrm{RH})$ messenger ribonucleic acid and the presence of biologically active GH-RH in human breast, endometrial, and ovarian cancers. J Clin Endocrinol Metab 84:582-589 